\title{
ESTUDO COMPARATIVO ENTRE OS INVENTÁRIOS DA CAVIDADE ABDOMINAL PELOS MÉTODOS VIDEOLAPAROSCÓPICO E LAPAROTÔMICO NO TRAUMA ABDOMINAL
}

\author{
COMPARATIVE STUDY OF THE EVALUATION OF THE ABDOMINAL CAVITY \\ BY VIDEOLAPAROSCOPIC AND LAPAROTOMIC METHODS \\ IN ABDOMINAL TRAUMA
}

\author{
Grijalva Otávio Ferreira da Costa,ACBC-CE ${ }^{1}$ \\ Antônio Ribeiro da Siva Filho, TCBC-CE ${ }^{2}$ \\ José Gomes Bezerra Filho ${ }^{3}$
}

\begin{abstract}
RESUMO: Objetivo: Comparar os inventários da cavidade abdominal, quanto à visibilização das estruturas anatômicas, realizadas pelos métodos videolaparoscópico e laparotômico, no trauma abdominal. Método: De novembro de 2001 a fevereiro de 2002, 25 pacientes foram submetidos ao protocolo de pesquisa, sendo 21 do sexo masculino e quatro do feminino. A idade média foi de 30,88 anos, variando de 18 a 63 . O inventário videolaparoscópico foi realizado de forma padronizada e seqüencial. Em seguida, todos os pacientes foram laparotomizados e o inventário refeito com os mesmos critérios. As estruturas e vísceras abdominais foram classificadas em visualizadas, parcialmente visualizadas e não visualizadas. Resultados: No inventário videolaparoscópico, o lobo esquerdo do fígado, as cúpulas diafragmáticas, a vesícula biliar, a parede posterior da bexiga, o fundo de saco anterior e a face interna da parede abdominal foram completamente visualizadas em todos os casos. As demais estruturas e vísceras intra-abdominais foram completamente visualizadas em percentuais que variaram de $25 \%$ a $76 \%$. O inventário videolaparoscópico apresentou sensibilidade de 45,45\%, especificidade de $100 \%$, valor preditivo positivo de $100 \%$ e valor preditivo negativo de $20 \%$. O inventário laparotômico identificou 78 injúrias e o videolaparoscópico 56. Conclusões: O inventário videolaparoscópico no trauma abdominal não é eficiente para a visualização e diagnóstico das lesões intra-abdominais. Entretanto é confiável nas dúvidas de penetração para a cavidade abdominal, no diagnóstico das lesões diafragmáticas e tóraco-abdominais, e para excluir lesões da parede anterior do esôfago, estômago e duodeno, parede posterior da bexiga e da vesícula biliar.
\end{abstract}

Descritores: Trauma; Abdome; Laparoscopia; Videolaparoscopia.

\section{INTRODUÇÃO}

A avaliação do trauma abdominal, apesar dos avanços médicos, continua desafiando os cirurgiões nas unidades de emergência. $\mathrm{O}$ abdome é aquele que mais oculta lesões teoricamente tratáveis dentre os segmentos corporais afetados por ferimentos traumáticos. Quando o diagnóstico e o tratamento são instituídos imediatamente, as chances de sobrevida são grandes, mesmo em pacientes com graves lesões ${ }^{1}$.

O exame físico minucioso, realizado de forma seqüencial e repetida, pelo mesmo examinador, associado a um alto índice de suspeição e a utilização de métodos auxiliares de diagnóstico, como o lavado peritoneal, a ultrasonografia e a tomografia computadorizada do abdome, pode, isoladamente ou em conjunto, fornecer ao cirurgião

1. Mestrando do Programa de Pós-Graduação em Bases da Técnica Cirúrgica e Cirurgia Experimental do Departamento de Cirurgia da Universidade Federal do Ceará. Preceptor da Residência de Cirurgia Geral do Instituto Dr. José Frota, Fortaleza-CE.

2. Doutor em Medicina, Professor Titular do Departamento de Morfologia da Universidade Federal do Ceará.

3. Professor da Disciplina de Bioestatística da Universidade Federal do Ceará.

Recebido em 05/03/2002

Aceito para publicação em 14/05/2002

Trabalho realizado no Instituto Dr. José Frota, Fortaleza, Ceará. 
do trauma subsídios para a indicação de laparotomia exploradora $^{2}$.

Esta continua sendo o procedimento padrão para o diagnóstico e tratamento das lesões traumáticas do abdome. Em algumas situações estas lesões são mínimas ou sequer existem, tornando a laparotomia desnecessária ${ }^{3-6}$. Os ferimentos penetrantes da transição tóraco-abdominal, dos flancos e os tangenciais do abdome são as lesões traumáticas que mais dúvidas suscitam quanto à violação da cavidade abdominal e à presença de lesões cirurgicamente tratáveis.

Nos últimos anos a videolaparoscopia vem sendo utilizada tanto para diagnóstico como tratamento das lesões abdominais evitando a laparotomia. Inicialmente foi indicada para as lesões penetrantes e mais recentemente para as lesões contusas da cavidade abdominal.

Ainda são muitas as dúvidas acerca do real papel deste método no trauma ${ }^{7,8}$. Entre elas uma parece ser capital: é possível ver todas as estruturas anatômicas intraabdominais pelo método videolaparoscópico assim como o é pelo método laparotômico?

Com o objetivo de comparar a eficiência do inventário da cavidade abdominal, quanto à visualização das estruturas anatômicas, entre os métodos videolaparoscópico e laparotômico, realizou-se este estudo.

\section{MÉTODO}

Foram estudados 25 pacientes vítimas de traumas abdominais contusos e penetrantes admitidos no Instituto Dr. José Frota, Fortaleza, Ceará, no período de novembro de 2001 a fevereiro de 2002, sendo 21 do sexo masculino e quatro do feminino, com as idades variando entre $18 \mathrm{e}$ 63 anos e média de 30,88 anos. Dezessete pacientes foram vítimas de traumas penetrantes, 11 por arma branca e seis por arma de fogo. Os restantes apresentavam traumas contusos dos quais seis por acidentes automobilísticos e dois por agressões físicas. O protocolo foi analisado e aprovado pela Comissão de Ética em Pesquisa da Universidade Federal do Ceará e Comissão de Ética Médica do Instituto Dr José Frota.

Os pacientes foram inicialmente avaliados seguindo os conceitos do Suporte Avançado de Vida no Trauma (ATLS). Aqueles que se enquadravam no protocolo de pesquisa eram informados do estudo e assinavam o termo de consentimento constante no projeto de pesquisa. Os critérios de inclusão no estudo foram: pacientes com pressão arterial sistólica mantida acima de $90 \mathrm{mmHg}$, necessidade de até 2 litros de Ringer-lactato para manutenção da pressão arterial sistólica acima de $90 \mathrm{mmHg}$, freqüência respiratória entre 10 e 29irpm e escala de coma de Glasgow igual a 15. Foram excluídos os pacientes com instabilidade hemodinâmica, os menores de 18 anos, as grávidas, os obesos mórbidos e os previamente laparotomizados (incisão mediana supra e/ou infra-umbilical) ${ }^{9}$.

Todos os pacientes foram submetidos à anestesia geral inalatória, com passagem de sondas vesical e nasogástrica após a intubação orotraqueal. Iniciou-se o procedimento cirúrgico pelo inventário videolaparoscópico com a confecção de quatro portais, sendo o primeiro na linha média na metade da distância entre o apêndice xifóide e o púbis. O pneumoperitônio foi feito com a utilização da agulha de Veress e passagem do trocarte pela técnica fechada. A pressão intra-abdominal foi mantida, no máximo, em $12 \mathrm{mmHg}$. Após a introdução da ótica de $30^{\circ}$ os outros trocartes foram introduzidos sob visão direta, iniciando-se pelo da linha média a $2 \mathrm{~cm}$ do apêndice xifóide, seguindo-se pelo da linha média na transição entre o terço médio e o distal da distância entre a cicatriz umbilical e o púbis e terminando pelo trocarte localizado na borda lateral do reto abdominal à esquerda, na metade da distância entre o umbigo e o púbis. Imediatamente iniciou-se a inspeção da cavidade abdominal pelo método videolaparoscópico.

As estruturas anatômicas e vísceras abdominais avaliadas foram: diafragma, fígado, baço, parede anterior do esôfago, estômago e duodeno, jejuno, íleo, apêndice, cólons direito, transverso, esquerdo e sigmóide, reto, goteiras parietocólica direita e esquerda, fundo de saco anterior e posterior e face interna da parede abdominal.

O inventário videolaparoscópico começou pelo andar superior do abdome para visualizar o fígado, o baço, as cúpulas diafragmáticas, o esôfago, a parede anterior do estômago e a vesícula biliar. Continuou pela goteira parietocólica direita, parede posterior da bexiga, fundo de saco anterior, goteira parietocólica esquerda e terminou pela mobilização dos cólons, reto e o rolamento de alças de delgado. Em todo o inventário foram usadas duas pinças de Babcock e uma reta para tração e afastamento das estruturas e vísceras. Não houve secção de ligamentos ou outras estruturas para facilitar a investigação. Usaram-se, quando necessário, mudanças de inclinação da mesa cirúrgica, com o objetivo de facilitar a visualização das estruturas intra-abdominais. Esta foi considerada como satisfatória quando a víscera abdominal ou a estrutura anatômica analisada foi completamente visualizada e em não satisfatória quando parcialmente visualizada ou nãovisualizada.

O inventário, levando-se em conta o conjunto de todas as estruturas avaliadas, foi considerado satisfatório quando todas as estruturas foram completamente visualizadas e todas as lesões existentes classificadas. Todas as outras possibilidades classificaram o inventário como não satisfatório (Tabela 1).

Após o inventário videolaparoscópico era feita uma laparotomia convencional. Uma incisão mediana supra e infra-umbilical foi realizada e o procedimento do inventário da cavidade abdominal refeito, utilizando as mesmas sequiência e padronização utilizadas no procedimento videolaparoscópico. Após o término do inventário laparotômico, as lesões encontradas foram tratadas concluindo-se o procedimento com o fechamento da parede abdominal.

Ao final dos inventários as lesões diagnosticadas eram registradas e classificadas segundo a Sociedade Americana de Cirurgia do Trauma. Os diagnósticos de todas as lesões de cada paciente, em conjunto, eram comparados e classificados em verdadeiro-positivo, verdadei- 
Tabela 1

Classificação dos inventários videolaparoscópico e laparotômico

\begin{tabular}{|c|c|c|c|c|c|}
\hline & \multicolumn{3}{|c|}{ Visibilização das estruturas } & \multicolumn{2}{|c|}{ Classificação das lesões } \\
\hline & Completa & Parcial & Não & Classificadas & Não-classificadas \\
\hline Satisfatório & Todas & Nenhuma & Nenhuma & Todas & Nenhuma \\
\hline Não-satisfatório & Não avaliado & 1 ou mais & 1 ou mais & Não avaliado & 1 ou mais \\
\hline
\end{tabular}

ro-negativo, falso-positivo ou falso-negativo. Todos os pacientes foram observados até a alta hospitalar e as complicações e os tempos de permanência, registrados no protocolo de pesquisa.

Os dados foram compilados em protocolo de pesquisa apropriado e realizadas comparações entre os métodos videolaparoscópico e laparotômico quanto à visualização das estruturas e vísceras intraperitoneais, aos resultados dos inventários, às lesões encontradas, à eficiência e aos tempos de realização dos inventários.

A análise estatística da amostra mostrou tratar-se de um estudo prospectivo autopareado. A sensibilidade, a especificidade, o valor preditivo positivo e negativo foram calculados para os métodos em questão. As amostras foram comparadas pelo teste qui-quadrado de McNemar com um grau de liberdade, considerando um valor significante quando $\mathrm{p}<0,05$.

\section{RESULTADOS}

Os resultados obtidos dos inventários videolaparoscópicos mostraram que o lobo esquerdo do fígado, as cúpulas diafragmáticas direita e esquerda, a vesícula biliar, a parede posterior da bexiga, o fundo-de-saco anterior e a face interna da parede abdominal foram completamente visualizados em todos os casos da amostra. As paredes anteriores do esôfago, estômago e duodeno, assim como as goteiras parietocólica direita e esquerda foram completamente visualizadas em $96 \%$ dos casos. O baço, para efeito de pesquisa, foi subdividido em faces visceral e diafragmática. A face visceral foi completamente visualizada em $16 \%$ dos casos, parcialmente visualizada em $44 \%$ e não visualizada em $28 \%$. Na face diafragmática os números foram $36 \%, 36 \%$ e $28 \%$, respectivamente. O lobo direito do fígado foi completamente visualizado em $96 \%$ dos casos e em $4 \%$ parcialmente visualizado. $\mathrm{O}$ jejuno foi completamente visualizado em 19 (76\%) casos e parcialmente em $6(24 \%)$. O íleo foi completamente visualizado em $20(80 \%)$ casos e parcialmente em cinco (20\%). O apêndice vermiforme foi completamente visualizado em $70 \%$ dos casos, parcialmente em $13 \%$ e não visualizado em $17 \%$, com um caso onde inexistia o órgão, pois, o paciente fora previamente apendicectomizado.

Os cólons direito, esquerdo, transverso e sigmóide foram completamente visualizados em percentuais que variaram de $52 \%$ a $64 \%$, parcialmente visualizados entre $32 \%$ e $44 \%$ dos casos e não visualizados em $4 \%$ a $8 \%$ dos casos. O reto foi a víscera oca com menor percentual de casos completamente visualizados $(28 \%)$, sendo na amostra, parcialmente visualizado em $44 \%$ dos casos e não visualizado em $28 \%$. Dos órgãos genitais internos femininos, o útero e as tubas uterina foram visualizados em metade das pacientes e não visualizados nos outros dois casos. Os ovários foram completamente visualizados em uma oportunidade e parcialmente visualizados nas outras três. $\mathrm{O}$ fundo de saco posterior não foi visualizado em nenhum caso (Tabela 2).

Quanto aos inventários laparotômicos o baço, em um caso, foi parcialmente visualizado, tanto referente à sua face visceral quanto à diafragmática. $\mathrm{O}$ útero, as tubas uterinas, e os ovários foram completamente visualizados em três dos quatro casos. No caso remanescente, o útero foi parcialmente visualizado e as tubas uterinas e os ovários não o foram. Todas as demais vísceras e estruturas intra-abdominais analisadas pelo método laparotômico foram completamente visualizadas em $100 \%$ (Tabela 3).

A qualidade dos inventários quanto à visualização, foi considerada não-satisfatória em $92 \%$ dos casos e satisfatória em $8 \%$, em relação ao método videolaparoscópico. Já nos inventários laparotômicos, $96 \%$ foram considerados satisfatórios e em um único caso não-satisfatório.

Os métodos videolaparoscópico e laparotômico foram comparados quanto à qualidade da visualização usando-se o teste qui-quadrado de McNemar com um grau de liberdade e considerando-se $\mathrm{p}<0,05$. O resultado evidenciou diferença de visualização estatística com relação as seguintes estruturas anatômicas e vísceras: baço face visceral e diafragmática, jejuno, apêndice vermiforme, cólons direito, esquerdo, transverso e sigmóide, reto e fundo de saco posterior.

O inventário videolaparoscópico evidenciou 56 lesões, enquanto o laparotômico diagnosticou 78. Das 22 injúrias não diagnosticadas metade encontrava-se no jejuno e íleo. Nenhuma das quatro lesões localizadas nos cólons foi evidenciada pela videolaparoscopia. Três lesões hepáticas, duas gástricas, uma esplênica e uma renal não foram diagnosticadas pelo inventário videolaparoscópico. Todas as lesões do diafragma, da vesícula e do mesentério foram evidenciadas e classificadas por ambos os inventários (Tabela 4).

Os métodos foram analisados quanto à possibilidade de identificar e classificar as lesões das vísceras e parede abdominais. $\mathrm{O}$ inventário videolaparoscópico quanto à 
Tabela 2

Relação entre as estruturas e vísceras intra-abdominais e o resultado dos inventários videolaparoscópicos

\begin{tabular}{|c|c|c|c|c|c|c|c|c|}
\hline & \multirow{2}{*}{\multicolumn{2}{|c|}{$\begin{array}{c}\text { Satisfatório } \\
\text { Comp. visibilizado }\end{array}$}} & \multicolumn{4}{|c|}{ Não-satisfatório } & & \\
\hline & & & \multicolumn{2}{|c|}{ Parc. visibilizado } & \multicolumn{2}{|c|}{ Não-visibilizado } & \multicolumn{2}{|c|}{ Total } \\
\hline & $n$ & $\%$ & $n$ & $\%$ & $n$ & $\%$ & $n$ & $\%$ \\
\hline Fígado lobo direito & 24 & $96 \%$ & 1 & $4 \%$ & 0 & $0 \%$ & 25 & $100 \%$ \\
\hline Fígado lobo esquerdo & 25 & $100 \%$ & 0 & $0 \%$ & 0 & $0 \%$ & 25 & $100 \%$ \\
\hline Baço face visceral & 9 & $36 \%$ & 9 & $36 \%$ & 7 & $28 \%$ & 25 & $100 \%$ \\
\hline Baço face hilar & 4 & $16 \%$ & 11 & $44 \%$ & 10 & $40 \%$ & 25 & $100 \%$ \\
\hline Diafragma direito & 25 & $100 \%$ & 0 & $0 \%$ & 0 & $0 \%$ & 25 & $100 \%$ \\
\hline Diafragma esquerdo & 25 & $100 \%$ & 0 & $0 \%$ & 0 & $0 \%$ & 25 & $100 \%$ \\
\hline Esôfago parede ant. & 25 & $100 \%$ & 0 & $0 \%$ & 0 & $0 \%$ & 25 & $100 \%$ \\
\hline Estômago parede ant. & 24 & $96 \%$ & 0 & $0 \%$ & 1 & $4 \%$ & 25 & $100 \%$ \\
\hline Duodeno & 24 & $96 \%$ & 1 & $4 \%$ & 0 & $0 \%$ & 25 & $100 \%$ \\
\hline Jejuno & 19 & $76 \%$ & 6 & $24 \%$ & 0 & $0 \%$ & 25 & $100 \%$ \\
\hline Íleo & 20 & $80 \%$ & 5 & $20 \%$ & 0 & $0 \%$ & 25 & $100 \%$ \\
\hline Apêndice & 17 & $70 \%$ & 3 & $13 \%$ & 4 & $17 \%$ & 24 & $100 \%$ \\
\hline Cólon direito & 16 & $64 \%$ & 8 & $32 \%$ & 1 & $4 \%$ & 25 & $100 \%$ \\
\hline Cólon transverso & 15 & $60 \%$ & 9 & $36 \%$ & 1 & $4 \%$ & 25 & $100 \%$ \\
\hline Cólon esquerdo & 13 & $52 \%$ & 11 & $44 \%$ & 1 & $4 \%$ & 25 & $100 \%$ \\
\hline Sigmóide & 15 & $60 \%$ & 8 & $32 \%$ & 2 & $8 \%$ & 25 & $100 \%$ \\
\hline Reto & 7 & $28 \%$ & 11 & $44 \%$ & 7 & $28 \%$ & 25 & $100 \%$ \\
\hline Útero & 2 & $50 \%$ & 0 & $0 \%$ & 2 & $50 \%$ & 4 & $100 \%$ \\
\hline Tuba uterina direita & 2 & $50 \%$ & 0 & $0 \%$ & 2 & $50 \%$ & 4 & $100 \%$ \\
\hline Tuba uterina esquerda & 2 & $50 \%$ & 0 & $0 \%$ & 2 & $50 \%$ & 4 & $100 \%$ \\
\hline Ovário direito & 1 & $25 \%$ & 0 & $0 \%$ & 3 & $75 \%$ & 4 & $100 \%$ \\
\hline Ovário esquerdo & 1 & $25 \%$ & 0 & $0 \%$ & 21 & $75 \%$ & 4 & $100 \%$ \\
\hline Vesícula biliar & 25 & $100 \%$ & 0 & $0 \%$ & 0 & $0 \%$ & 25 & $100 \%$ \\
\hline Bexiga & 25 & $100 \%$ & 0 & $0 \%$ & 0 & $0 \%$ & 25 & $100 \%$ \\
\hline Goteira par. cólica dir. & 24 & $96 \%$ & 1 & $4 \%$ & 0 & $0 \%$ & 25 & $100 \%$ \\
\hline Goteira par. cólica esq. & 24 & $96 \%$ & 1 & $4 \%$ & 0 & $0 \%$ & 25 & $100 \%$ \\
\hline Fundo de saco anterior & 25 & $100 \%$ & 0 & $0 \%$ & 0 & $0 \%$ & 25 & $100 \%$ \\
\hline Fundo de saco posterior & 0 & $0 \%$ & 1 & $4 \%$ & 24 & $96 \%$ & 25 & $100 \%$ \\
\hline Parede abdominal ant. & 25 & $100 \%$ & 0 & $0 \%$ & 0 & $0 \%$ & 25 & $100 \%$ \\
\hline
\end{tabular}

Comp $=$ Completamente, Parc $=$ Parcialmente

capacidade de diagnosticar as lesões apresentou sensibilidade de $45,45 \%$, especificidade de $100 \%$, valor preditivo positivo de $100 \%$ e valor preditivo negativo de $20 \%$. Quanto ao inventário laparotômico, todos os valores analisados foram iguais a $100 \%$ (Tabela 5 ).

O tempo gasto para a realização do inventário videolaparoscópico foi de 31 minutos em média, variando de 18 a 45. Na laparotomia exploradora foram gastos 11 minutos em média com o mínimo de cinco e o máximo de 18.

O tempo médio de internação foi de 6,35 dias com um mínimo de dois e o máximo de 31 dias. Não houve óbitos nem complicações relacionadas aos métodos de inventário e tratamento das lesões abdominais. 
Tabela 3

Relação entre as estruturas e vísceras intra-abdominais e o resultado dos inventários laparotômicos

\begin{tabular}{|c|c|c|c|c|c|c|c|c|}
\hline & \multirow{2}{*}{\multicolumn{2}{|c|}{$\begin{array}{c}\text { Satisfatório } \\
\text { Comp. visibilizado }\end{array}$}} & \multicolumn{4}{|c|}{ Não-satisfatório } & \multirow{2}{*}{\multicolumn{2}{|c|}{ Total }} \\
\hline & & & \multicolumn{2}{|c|}{ Parc. visibilizado } & \multicolumn{2}{|c|}{ Não-visibilizado } & & \\
\hline & $n$ & $\%$ & $n$ & $\%$ & $n$ & $\%$ & $n$ & $\%$ \\
\hline Fígado lobo direito & 25 & $100 \%$ & 0 & $0 \%$ & 0 & $0 \%$ & 25 & $100 \%$ \\
\hline Fígado lobo esquerdo & 25 & $100 \%$ & 0 & $0 \%$ & 0 & $0 \%$ & 25 & $100 \%$ \\
\hline Baço face visceral & 24 & $96 \%$ & 0 & $0 \%$ & 1 & $4 \%$ & 25 & $100 \%$ \\
\hline Baço face hilar & 24 & $96 \%$ & 1 & $4 \%$ & 0 & $0 \%$ & 25 & $100 \%$ \\
\hline Diafragma direito & 25 & $100 \%$ & 0 & $0 \%$ & 0 & $0 \%$ & 25 & $100 \%$ \\
\hline Diafragma esquerdo & 25 & $100 \%$ & 0 & $0 \%$ & 0 & $0 \%$ & 25 & $100 \%$ \\
\hline Esôfago parede ant. & 25 & $100 \%$ & 0 & $0 \%$ & 0 & $0 \%$ & 25 & $100 \%$ \\
\hline Estômago parede ant. & 25 & $100 \%$ & 0 & $0 \%$ & 0 & $0 \%$ & 25 & $100 \%$ \\
\hline Duodeno & 25 & $100 \%$ & 0 & $0 \%$ & 0 & $0 \%$ & 25 & $100 \%$ \\
\hline Jejuno & 25 & $100 \%$ & 0 & $0 \%$ & 0 & $0 \%$ & 25 & $100 \%$ \\
\hline Íleo & 25 & $100 \%$ & 0 & $0 \%$ & 0 & $0 \%$ & 25 & $100 \%$ \\
\hline Apêndice & 24 & $100 \%$ & 0 & $0 \%$ & 0 & $0 \%$ & 24 & $100 \%$ \\
\hline Cólon direito & 25 & $100 \%$ & 0 & $0 \%$ & 0 & $0 \%$ & 25 & $100 \%$ \\
\hline Cólon transverso & 25 & $100 \%$ & 0 & $0 \%$ & 0 & $0 \%$ & 25 & $100 \%$ \\
\hline Cólon esquerdo & 25 & $100 \%$ & 0 & $0 \%$ & 0 & $0 \%$ & 25 & $100 \%$ \\
\hline Sigmóide & 25 & $100 \%$ & 0 & $0 \%$ & 0 & $0 \%$ & 25 & $100 \%$ \\
\hline Reto & 25 & $100 \%$ & 0 & $0 \%$ & 0 & $0 \%$ & 25 & $100 \%$ \\
\hline Útero & 3 & $75 \%$ & 1 & $25 \%$ & 0 & $0 \%$ & 4 & $100 \%$ \\
\hline Tuba uterina direita & 3 & $75 \%$ & 0 & $0 \%$ & 1 & $25 \%$ & 4 & $100 \%$ \\
\hline Tuba uterina esquerda & 3 & $75 \%$ & 0 & $0 \%$ & 1 & $25 \%$ & 4 & $100 \%$ \\
\hline Ovário direito & 3 & $75 \%$ & 0 & $0 \%$ & 1 & $25 \%$ & 4 & $100 \%$ \\
\hline Ovário esquerdo & 3 & $75 \%$ & 0 & $0 \%$ & 1 & $25 \%$ & 4 & $100 \%$ \\
\hline Vesícula biliar & 25 & $100 \%$ & 0 & $0 \%$ & 0 & $0 \%$ & 25 & $100 \%$ \\
\hline Bexiga & 25 & $100 \%$ & 0 & $0 \%$ & 0 & $0 \%$ & 25 & $100 \%$ \\
\hline Goteira par. cólica dir. & 25 & $100 \%$ & 0 & $0 \%$ & 0 & $0 \%$ & 25 & $100 \%$ \\
\hline Goteira par. cólica esq. & 25 & $100 \%$ & 0 & $0 \%$ & 0 & $0 \%$ & 25 & $100 \%$ \\
\hline Fundo de saco anterior & 25 & $100 \%$ & 0 & $0 \%$ & 0 & $0 \%$ & 25 & $100 \%$ \\
\hline Fundo de saco posterior & 25 & $100 \%$ & 0 & $0 \%$ & 0 & $0 \%$ & 25 & $100 \%$ \\
\hline Parede abdominal ant. & 25 & $100 \%$ & 0 & $0 \%$ & 0 & $0 \%$ & 25 & $100 \%$ \\
\hline
\end{tabular}

Comp $=$ Completamente, Parc $=$ Parcialmente.

\section{DISCUSSÃO}

O desafio médico de investigar a cavidade abdominal sem abri-la é antigo. As primeiras tentativas bem-sucedidas foram feitas por Georg Kelling e Dimitri Ott em 1901, cabendo ao primeiro as honras de realizar um procedimento que muito se assemelhava com a laparosco- pia $^{10}$. Desde então o procedimento vem evoluindo, inicialmente quanto ao diagnóstico de afecções abdominais e por fim para o trauma. No trauma, Lamy e Sarles foram os primeiros a utilizar a laparoscopia no diagnóstico das lesões intra-abdominais, em $1956^{11}$. Os primeiros estudos que analisaram a laparoscopia como método diagnóstico no trauma correlacionando os seus achados com a laparo- 
Tabela 4

Número de lesões e percentual por víscera e estrutura anatômica de acordo com os métodos de diagnóstico

\begin{tabular}{l|rr|r|c}
\hline & \multicolumn{2}{|c|}{ Videolaparoscópico } & \multicolumn{2}{c}{ Laparotômico } \\
\cline { 2 - 5 } & $n$ & $\%$ & $n$ & $\%$ \\
\hline Diafragma & 3 & $100 \%$ & 3 & $100 \%$ \\
Fígado & 11 & $78 \%$ & 14 & $100 \%$ \\
Baço & 3 & $75 \%$ & 4 & $100 \%$ \\
Estômago & 2 & $50 \%$ & 4 & $100 \%$ \\
Jejuno e íleo & 17 & $61 \%$ & 28 & $100 \%$ \\
Cólon direito & 0 & $0 \%$ & 2 & $100 \%$ \\
Cólon transverso & 0 & $0 \%$ & 1 & $100 \%$ \\
Cólon esquerdo & 0 & $0 \%$ & 1 & $100 \%$ \\
Vesícula biliar & 1 & $100 \%$ & 1 & $100 \%$ \\
Mesentérico & 1 & $100 \%$ & 1 & $100 \%$ \\
Rim direito & 0 & $0 \%$ & 1 & $100 \%$ \\
Parede abdominal & 18 & $100 \%$ & 18 & $100 \%$ \\
\hline Total & 56 & $71 \%$ & 78 & $100 \%$ \\
\hline
\end{tabular}

tomia foram feitos por Gazzaniga et al. e Carnevalle et al., em 1976 e 1977 respectivamente ${ }^{12,13}$. Entretanto, o grande avanço do método ocorreu com advento da videolaparoscopia em 1986. Coube a Phillipe Mouret, após 10 mil cirurgias realizadas, propor em 1990 regras para execução e treinamento, além de determinar as vantagens e limitações da cirurgia endoscópica intraperitoneal ${ }^{14}$. Desde então, vários autores passaram a utilizar a videolaparoscopia como método de diagnóstico e tratamento. Zantut, Ivatury e Smith publicaram, em 1997, trabalho multicêntrico com 510 pacientes, usando a videolaparoscopia no trauma penetrante para diagnóstico e terapêutica, evitando em $54,3 \%$ dos pacientes a laparotomia exploradora ${ }^{15}$.

Apesar do grande número de trabalhos publicados sobre o assunto, uma dúvida ainda é pertinente: qual a possibilidade de realizar o inventário da cavidade abdominal visualizando todas as estruturas intra-abdominais tal qual se faz na laparotomia exploradora?

A primeira grande questão encontrada foi a escolha dos locais de colocação dos trocartes, pois se sabe que é possível a visualização de todas as vísceras e estruturas anatômicas intra-abdominais pela videolaparoscopia, desde que se utilizem portais selecionados para tal. No presente estudo adotou-se a padronização proposta pelo grupo de cirurgia do trauma da Universidade de São Paulo, acrescentando um quarto portal na linha média a $2 \mathrm{~cm}$ do apêndice xifóide. Aparentemente estes foram os locais que mais se adaptaram à necessidade de avaliar toda a cavidade abdominal ${ }^{15}$.

A dificuldade de visualização das vísceras ocas e a não identificação das lesões, como demonstradas nesta análise, já haviam sido relatadas por diversos autores como Fabian, Simon e Poole ${ }^{16-18}$. Nesta casuística, excetuandose as paredes anteriores do esôfago, estômago e duodeno, todas as demais vísceras ocas tiveram percentuais de visualização parcial que variaram entre $20 \%$ e $44 \%$ e não visualização que oscilaram de $4 \%$ a $8 \%$.

$\mathrm{O}$ fígado foi a víscera maciça com maior percentual de completa visualização, cerca 96\%, pelo método videolaparoscópico. Apenas em um único caso o lobo direito do fígado foi parcialmente visualizado em função de aderências existentes com a cúpula diafragmática direita. Não fosse esta particularidade, tal víscera seria completamente visualizada em todos os casos.

O baço, em especial, necessitou de manobras para a sua visualização. A tração da grande curvatura gástrica no sentido caudal, usando-se uma pinça babcock laparoscópica, ajudou na maioria dos casos, mas em $24 \%$ dos pacientes não houve qualquer visualização desta víscera. Esta dificuldade já havia sido detectada por Berci et al., que utilizaram como indício indireto de lesão esplênica a observação de sangramento contínuo e cumulativo na goteira parietocólica esquerda e espaço subfrênico esquerdo ${ }^{19}$.

As cúpulas diafragmáticas direita e esquerda, as goteiras parietocólica direita e esquerda, o fundo-do-saco anterior, a parede posterior da bexiga e a face interna da parede abdominal foram completamente visualizadas em pelo menos $96 \%$ dos casos. Este resultado assegura que o método videolaparoscópico, como exame diagnóstico, pode excluir com segurança todos os casos onde existam dúvidas de penetração à cavidade abdominal. Estes dados já haviam sido observados por Sosa et al. que, analisando 121 pacientes, vítimas de ferimentos por armas de fogo no abdome, demonstraram $0 \%$ de falso-negativo quando avaliaram a violação peritoneal ${ }^{20}$.

Os órgãos genitais femininos em geral são facilmente visualizados desde que se utilize um levantador de útero e óticas de $30^{\circ}$, com portais direcionados para a pelve. Neste estudo, apesar da não utilização destes artifícios, foi possível visualizar completamente estas estruturas em 50\% dos casos. Curiosamente, em uma das pacientes havia um bloqueio inflamatório e aderencial que na laparotomia foi confirmado e a biopsia realizada posteriormente revelou tratar-se de tuberculose peritoneal.

As análises da sensibilidade, especificidade, valor preditivo positivo e negativo variam muito nos artigos já publicados, principalmente porque os critérios para avaliação diferem muito na sua essência. Ivatury et al., analisando o método videolaparoscópico no trauma abdominal penetrante, com atenção especial às lesões diafragmáticas, concluíram que a sensibilidade e especificidade eram de $87 \%$ e $100 \%$ respectivamente. Quando a análise se restringia a região tóraco-abdominal, a sensibilidade foi de $97 \%$. Nas regiões epigástrica e flancos, entretanto, a sensibilidade foi de $43 \%{ }^{21}$. Sosa et al., no seu estudo analisando a penetração peritoneal pelo método videolaparoscópico, quanto à penetração peritoneal, encontraram $100 \%$ de sensibilidade, $98,7 \%$ de especificidade, $97,6 \%$ de valor preditivo positivo e $100 \%$ de valor preditivo negativo $^{20}$. Se fosse adotado, neste estudo, como critério o diag- 
Tabela 5

Relação dos achados dos inventários com a eficiência dos métodos

n $\quad$ Achados videolaparoscópicos

1 Hemoperitônio

2 Hemoperitônio

3 Hemoperitônio, diafragma 2 lesões, grau I e grau IV

4 Hemoperitônio, fígado 2 lacerações grau II

5 Nenhum

6 Hemoperitônio

7 Hemoperitônio, fígado 2 lacerações grau I

8 Nenhum

9 Hemoperitônio, estômago, hematoma na grande curvatura grau I, vesícula biliar, hematoma grau I

10 Hemoperitônio, íleo e jejuno 11 lesões grau II

11 Hemoperitônio, estômago 1 lesão grau I

12 Hemoperitônio, fígado hematoma grau II

13 Hemoperitônio, íleo 1 lesão grau II

14 Hemoperitônio, mesentério hematoma grau I, jejuno 1 lesão grau I

15 Hemoperitônio, fígado 3 lacerações grau I, baço 1 laceração grau I

16 Hemoperitônio, diafragma 1 lesão grau III, baço 1 hematoma grau I e 1 laceração grau I

17 Nenhum

18 Hemoperitônio, jejuno 2 lesões grau II

19 Hemoperitônio

20 Hemoperitônio

21 Hemoperitônio, fígado 3 lacerações, 1 grau III e 2 grau I

22 Hematoma da parede abdominal e fossa ilíaca esquerda

23 Laceração da parede abdominal anterior

24 Jejuno 2 lesões grau I

25 Hematoma da parede abdominal e parede posterior da bexiga

\begin{tabular}{|c|c|c|}
\hline Resultado & Achados laparotômicos & Resultado \\
\hline F. Negativo & Hemoperitônio, jejuno 3 lesões grau II & V. Positivo \\
\hline F. Negativo & Hemoperitônio,baço 1 laceração grau II & V. Positivo \\
\hline V. Positivo & $\begin{array}{l}\text { Hemoperitônio, diafragma } 2 \text { lesões, grau I } \\
\text { e grau IV }\end{array}$ & V. Positivo \\
\hline V. Positivo & Hemoperitônio, fígado 2 lacerações grau II & V. Positivo \\
\hline V. Negativo & Nenhum & V. Negativo \\
\hline F. Negativo & Hemoperitônio, fígado 1 laceração grau III & V. Positivo \\
\hline F. Negativo & $\begin{array}{l}\text { Hemoperitônio, fígado } 3 \text { lacerações grau I, } \\
\text { diafragma } 2 \text { lesões grau II, cólon } 2 \text { lesões } \\
\text { grau II }\end{array}$ & V. Positivo \\
\hline V. Negativo & Nenhum & V. Negativo \\
\hline F. Negativo & $\begin{array}{l}\text { Hemoperitônio, estômago, hematoma na } \\
\text { grande curvatura grau I, vesícula biliar } \\
\text { hematoma grau I, fígado } 1 \text { laceração grau I }\end{array}$ & V. Positivo \\
\hline F. Negativo & $\begin{array}{l}\text { Hemoperitônio, íleo e jejuno } 11 \text { lesões } \\
\text { grau II, cólon transverso } 1 \text { lesão grau II }\end{array}$ & V. Positivo \\
\hline V. Positivo & Hemoperitônio, estômago 1 lesão grau I & V. Positivo \\
\hline V. Positivo & Hemoperitônio, fígado hematoma grau II & V. Positivo \\
\hline F. Negativo & Hemoperitônio, íleo 2 lesões grau II & V. Positivo \\
\hline F. Negativo & $\begin{array}{l}\text { Hemoperitônio, mesentério hematoma } \\
\text { grau I, jejuno } 1 \text { lesão grau I, estômago } 1 \\
\text { lesão grau I }\end{array}$ & V. Positivo \\
\hline F. Negativo & $\begin{array}{l}\text { Hemoperitônio, fígado } 3 \text { lacerações grau I, } \\
\text { baço } 1 \text { laceração grau I, estômago } 1 \text { lesão } \\
\text { grau I }\end{array}$ & V. Positivo \\
\hline V. Positivo & $\begin{array}{l}\text { Hemoperitônio, diafragma } 1 \text { lesão grau III, } \\
\text { baço } 1 \text { hematoma grau I e } 1 \text { laceração grau I }\end{array}$ & V. Positivo \\
\hline V. Negativo & Nenhum & V. Negativo \\
\hline F. Negativo & Hemoperitônio, jejuno 4 lesões grau II & V. Positivo \\
\hline F. Negativo & $\begin{array}{l}\text { Hemoperitônio, jejuno } 1 \text { lesão grau I, } \\
\text { rim dir } 1 \text { lesão grau I }\end{array}$ & V. Positivo \\
\hline F. Negativo & $\begin{array}{l}\text { Hemoperitônio, jejuno } 4 \text { lesões grau II, } \\
\text { cólon esquerdo } 1 \text { lesão grau II }\end{array}$ & V. Positivo \\
\hline V. Positivo & $\begin{array}{l}\text { Hemoperitônio, fígado } 3 \text { lacerações, } \\
1 \text { grau III e } 2 \text { grau I }\end{array}$ & V. Positivo \\
\hline V. Positivo & $\begin{array}{l}\text { Hematoma da parede abdominal e fossa } \\
\text { ilíaca esquerda }\end{array}$ & V. Positivo \\
\hline V. Positivo & Laceração da parede abdominal anterior & V. Positivo \\
\hline V. Positivo & Jejuno 2 lesões grau I & V. Positivo \\
\hline V. Positivo & $\begin{array}{l}\text { Hematoma da parede abdominal e parede } \\
\text { posterior da bexiga }\end{array}$ & V. Positivo \\
\hline
\end{tabular}


Tabela 6

Sensibilidade, especificidade, valor preditivo positivo e negativo do diagnóstico videolaparoscópico de acordo com os grupos de vísceras e estrutruras anatômicas

\begin{tabular}{l|c|c|c|c}
\hline & Sensibilidade & Especificidade & V.P.Positivo & V.P.Negativo \\
\hline Diafragma, fígado e baço & $81,81 \%$ & $100 \%$ & $100 \%$ & $80,95 \%$ \\
Vísceras ocas & $51,35 \%$ & $100 \%$ & $100 \%$ & $43,75 \%$ \\
Parede abdominal anterior e flancos & $100 \%$ & $100 \%$ & $100 \%$ & $100 \%$ \\
Todas estruturas avaliadas & $45,45 \%$ & $100 \%$ & $100 \%$ & $20 \%$ \\
\hline
\end{tabular}

V.P. $=$ Valor preditivo

nóstico da penetração para a cavidade peritoneal, os resultados da sensibilidade, especificidade, valor preditivo positivo e negativo seriam de $100 \%$. Neste estudo, avaliando-se a possibilidade de visualizar e diagnosticar as lesões das vísceras intra-abominais e parede abdominal, a sensibilidade do método videolaparoscópico foi de $45,45 \%$, a especificidade de $100 \%$, o valor preditivo positivo de $100 \%$ e o valor preditivo negativo de apenas $20 \%$.

Townsend et al., no seu estudo, demonstraram benefício do inventário laparoscópico no diagnóstico e tratamento das lesões leves e moderadas dos órgãos sólidos no trauma contuso. Na sua amostra, o diagnóstico laparoscópico permitiu o tratamento não-cirúrgico em $100 \%$ dos pacientes. A visualização direta da lesão permitiu com segurança o não retardamento da laparotomia ${ }^{22}$.

Estratificando-se a análise por diagnóstico das lesões das vísceras ocas, da parede abdominal e do diafragma associado às vísceras maciças do andar superior do abdome foram obtidos resultados que comprovam a baixa sensibilidade e valor preditivo negativo do exame quanto à verificação de lesões das vísceras ocas (Tabela 6).

A laparotomia exploradora, por sua vez, resultou em completa visualização de quase todas as estruturas anatômicas com duas exceções: o baço e os ovários de uma paciente com múltiplas aderências inflamatórias não foram visualizados, e como não havia evidência direta de sangramento ou lesões nesses órgãos, optou-se pela não liberação das aderências.

Apesar da eficiência da laparotomia este procedimento não é isento de morbidade. Aumenta o tempo de permanência hospitalar quando comparado à videolaparoscopia. Weigelt et al., em 1988, publicaram uma análi- se de 248 pacientes submetidos à laparotomia não terapêutica, dos quais 185 com traumas penetrantes e 63 com trauma contusos. $\mathrm{O}$ trabalho evidenciou complicações pós-operatórias em 94 pacientes e obstrução intestinal por aderências ou bridas em cinco deles ${ }^{23}$.

$\mathrm{Na}$ laparotomia exploradora, a sensibilidade, a especificidade, o valor preditivo positivo e negativo para a avaliação da possibilidade de visualizar e diagnosticar as lesões traumáticas das vísceras intra-abdominais e parede abdominal foram de $100 \%$.

Das 78 lesões diagnosticadas pela laparotomia exploradora, 22 não foram visualizados pelo método videolaparoscópico, das quais 11 lesões no jejuno e íleo e quatro nos cólons. Comparando-se as amostras e analisando-as com o qui-quadrado de McNemar com $\mathrm{p}<0,05$, verificase que elas são discordantes com significância estatística.

Concluímos, portanto, que o método videolaparoscópico para o diagnóstico e classificação de lesões intraabdominais nos traumas penetrantes e contusos, de acordo com metodologia empregada, não é capaz de visualizar completamente todas as estruturas e vísceras avaliadas. Por sua vez, o método laparotômico se mostrou eficaz em 96\% dos casos.

A utilização do método videolaparoscópico deve ser restrita a casos selecionados quando houver dúvida na penetração para a cavidade abdominal, se os ferimentos de entrada forem nos flancos ou parede abdominal anterior, dúvida no diagnóstico de lesões diafragmáticas, necessidade de melhor avaliar as lesões hepáticas ou esplênicas e na exclusão de lesões da parede posterior da bexiga, vesícula biliar e paredes anteriores do esôfago, estômago e duodeno. 


\begin{abstract}
Background: To compare the evaluation of the abdominal cavity by videolaparoscopic and laparotomic methods, in patients sustaining abdominal trauma. Method: From November of 2001 to February of 2002, 25 patients were studied, being 21 males and four females. Average age was 30.88 years, varying from 18 to 63 . The videoendoscopic evaluation was carried through in a standardized and sequential form. After that, all the patients were laparotomised and the evaluation remade with the same criteria. Abdominal structures and viscera were classified as visualized, partially visualized, not visualized and non-existent. Results: In videolaparoscopic evaluation, the left lobe of the liver, the diaphragmatic domes, the gallbladder, the posterior wall of the bladder, anterior Douglas' cul-de-sac and the internal face of the abdominal wall were fully visualized in all cases. The others intra-abdominal structures and viscera were completely visualized in percentages that varied from $25 \%$ to $76 \%$. Videolaparoscopic evaluation presented sensitivity of $45.45 \%$, specificity of $100 \%$, positive predictive value of $100 \%$ and negative predictive value of $20 \%$. Laparotomic evaluation identified 78 injuries and videolaparoscopy 56. Conclusions: Videolaparoscopic evaluation in abdominal trauma is not effective in the visualization and diagnosis of intra-abdominal injuries. However it is sufficiently trustworthy in cases of doubts of penetration of the abdominal cavity, in the diagnostic of diaphragmatic and toraco-abdominal injuries and to exclude injuries of the anterior esophagus, stomach and duodenum wall, posterior wall of the bladder and gallbladder.
\end{abstract}

Key Words: Trauma; Abdomen; Laparoscopy; Videolaparoscopy.

\title{
REFERÊNCIAS
}

1. American College of Surgeons. Suporte Avançado de Vida no Trauma. $6^{\mathrm{a}}$ Edição, American College of Surgeons 1997 p. $159-175$

2. Fabian TC, Croce MA. Abdominal trauma, including indication for celiotomy, In: Feliciano DV, Moore EE, Mattox KL. Trauma. $3^{\text {rd }}$ ed Stanford: Appleton \& Lange 1996, chapt. 28, p. 441-459.

3. Sherman RT, Pavish RA. Management of shotgun injurie: a review of 152 cases. J Trauma 1963, 3-76.

4. Muchart DJJ, Abdool-Carrim ATO, King B. Selective conservative management of abdominal gunshot wounds: a prospective study. Br J Surg 1990, 77:652- 655.

5. Renz BM, Feliciano DV. Unnecessary laparotomies for trauma: a prospective study of morbidity. J Trauma 1995 , 38(3):350-356.

6. Lowe RJ, Saletta JD, Read DR et al. Should laparotomy be mandatory or selective in gunshot wounds of the abdomen? J Trauma 1977, 17(12):903-907.

7. Carrilho IJ, Zeitune JMR. Laparoscopia em urgências. Gastroenterol Endosc Digest 1983, 2:9-13.

8. Zantut LFC, Junior AJR, Birolini D. Laparoscopy as a diagnostic tool in the evaluation of trauma. Panam J Trauma 1990, 2:6-11.

9. Safran DB, Orlando III R. Physiologic effects of pneumoperitoneum. Am J Surg 1994, 167:281-286.

10. Stellato TA. History of laparoscopic surgery. Surg Clin Nor Am 1992, 72:997-1001.

11. Lamy R, Sarles H. Interêt de la peritonéoscopie chez le polytraumatisés. Mars Chir 1956, 8:82-85.

12. Gazzaniga AB, Stanton WW, Bartlett RH. Laparoscopy in the diagnosis of blunt and penetrating injuries to the abdomen. Am J Surg 1976, 131:315-319.

13. Carnevale N, Baron N, Delany HM. Peritoneoscopy as an aid in the diagnosis of abdominal trauma: a preliminary report. J Trauma 1977, 17:634-641.

14. Mouret P. La chirurgie par voie endoscopique. Chirurgie, $1990,116: 829-833$
15. Zantut LF, Ivatury RR, Porter JM et al. Diagnostic and therapeutic laparoscopy for penetrating abdominal trauma: A multicenter experience. J Trauma 1997, 42:825-830.

16. Fabian TC, Croce MA, Stewart RM et al. A prospective analysis of diagnostic laparoscopy in trauma. Ann Surg 1993, 217:557-561.

17. Simon RJ, Ivatury RR. Current concepts in the use of cavitary endoscopy in the evaluation and treatment of blunt and penetrating truncal injuries. Surg Clin Nor Am 1995, 75:157-174.

18. Poole GV, Thomae KR, Hauser CJ. Laparoscopy in trauma. Surg Clin Nor Am 1996, 76:547-556

19. Berci G, Sackier JM, Paz-Partlow M. Emergency laparoscopy. Am J Surg 1991, 161:332-335.

20. Sosa JL, Arrillaga A, Puente I et al. Laparoscopy in 121 consecutive patients with abdominal gunshot wounds. J Trauma 1995, 39:501-506.

21. Ivatury RR, Simon RJ, Stahl WM. A critical evaluation of laparoscopy in penetrating abdominal trauma. J Trauma 1993, 34:822-827.

22. Townsend MC, Flancbaum L, Choban PS et al. Diagnostic laparoscopy as an adjunct to selective conservative management of solid organ injuries after blunt abdominal trauma. J Trauma 1993, 35:647-651.

23. Weigelt JA, Kingman RG. Complications of negative laparotomy for trauma. Am J Surg 1988, 156:544-547.

Endereço para correspondência:

Dr. Grijalva Otávio Ferreira da Costa

Rua Silva Jatahy, 1155 - Meireles

60165-070 - Fortaleza-CE 